\title{
Application of Bond Graph approach in dynamic modelling of industrial gas turbine
}

\author{
Morteza Montazeri-Gh ${ }^{*}$ and Seyed Alireza Miran Fashandi \\ Systems Simulation and Control Laboratory, School of Mechanical Engineering, Iran University of Science and Technology, \\ Tehran, Iran
}

Received: 19 January 2017 / Accepted: 22 May 2017

\begin{abstract}
Nowadays, gas turbines play a significant role in industry and power generation units. Therefore, any increase in their performance efficiency, is designers' major concern. Power generation system's principal considerations are performance, weight and reliability. Gas turbine engine is considered as a probable choice for such applications. This research develops and validates a Bond Graph model based on flow of energy and information of a gas turbine engine. Here, modelling of the gas turbine engine is achieved based on the pseudo Bond Graph approach. Subsequently, by coupling the Bond-Graph component models, a unified framework for model representation is presented. Also, to study the effect of changing external load on turbine's performance, an industrial two-shaft gas turbine is simulated under large transient loads based on the previously developed component models. Finally, the commercial gas turbine simulation program (GSP) is used to validate the simulation results. Transient response simulations indicate an acceptable error between the GSP and Bond Graph model outputs.
\end{abstract}

Keywords: Dynamic performance / industrial gas turbine / Bond Graph approach / simulation

\section{Introduction}

Industrial gas turbines have a considerable potential to generate the electrical power and mechanical drive force. These turbines are used as the compressors derivers in the mechanical applications and as the generators derivers in the electrical applications for both open and combined cycles. Modeling of industrial gas turbines plays an important role in the design and development of the control and diagnosis systems.

One method that is easily available to the engineers to study the dynamic behavior of gas turbine systems is to develop mathematical models and do simulations in order to better understand the system dynamic behavior. However, the availability of a set of general mathematical models for gas turbine system modelling of the flexibility and level of complexity for the specific problem at hand is often limited. Also, it is necessary to model a complete gas turbine system available in different complexity levels to assemble into a full model for simulating by a desired simulator. Early models of gas turbines were the first-order linear models to relate the fuel flow (as an input parameter) and the turbine shaft rotational speed (as the output

\footnotetext{
*e-mails: montazeri@iust.ac.ir;
}

s.alireza.miran@gmail.com parameter). These models, which their constant coefficients were experimentally specified, were valid just in a limited performance range. Along with the development of first-order models (in the frequency domain), more parameters were gradually used for the calculation of the constants. Also by developing the previous models used only for the single-shaft turbines, new models were presented to simulate the two-shaft gas turbines [1-3].

After that time, due to the limited validity of that models (with time constants) and in order to enhance the flexibility of the designed models and meet the more needs, the researchers paid attention to non-linear and more complicated models. The first non-linear model of the gas turbine was presented by Saravanamuttoo and Fawke [4]. This thermodynamic model, obtained from the physical characteristics of the system, was able to predict the dynamic behavior of the turbine over the full performance range. Of course, later, more accurate and comprehensive models were introduced to simulate the transient behavior of the gas turbine [5]. Effectively using and developing the reusable models rely on a consistent framework for representing a successful model. Bond Graphs is considered as a probable choice to meet the requirements. To develop the gas turbine engine, the ever-increasing demand for gaining more power and lower fuel consumption has resulted in designs at or near the thermal, aerodynamic and 
Table 1. Design point characteristics of the examined gas turbine engine.

\begin{tabular}{ll}
\hline Quantity & Value \\
\hline Thermal efficiency, \% & 34.2 \\
Compressor pressure ratio & 14 \\
Power, MW & 24.77 \\
Exhaust gas temperature, ${ }^{\circ} \mathrm{C}$ & 543 \\
Exhaust gas flow, $\mathrm{kg} \mathrm{s}^{-1}$ & 80.4 \\
GG turbine speed, rpm & 9705 \\
Power turbine speed, rpm & 7700 \\
\hline
\end{tabular}

structural limits of the system components. It means that the effect of transient and dynamic instabilities which can cause the severe damage of the components must be quantified both from the individual components considerations, but also from aspect of a system approach. The Bond Graphs are such a modeling approach that has a potential to meet the needs $[1,5]$.

The Bond Graph modeling approach, working based on the energy balance and object-oriented concept, can cause to produce and develop a library of flexible models of the gas turbine system components. The Bond Graph method is efficiently capable of modeling the systems that have non-linear behaviors and are connected with different fields of the energy [6] (mechanical, hydraulic, electrical, pneumatics and thermodynamics systems). Thoma [7] was one of the first researchers in the field of thermo-fluid systems modeling by the Bond Graph method. He proposed the temperature as an effort variable and the entropy flow as the flow variable. Karnopp [8] in 1979 introduced the concept of pseudo Bond Graph for modeling of thermo-fluid systems.

Modeling of the gas turbine engine performance by the Bond Graph approach was done in $1972[9]$ at MIT University for the first time. The pressure, temperature and torque were considered as the effort variables, and the mass flow and engine speed (rpm) were considered as the flow variables. Then a simple cycle of the single-shaft gas turbine was modeled by implementing the physical laws and performance characteristic curves of the elements in the form of Bond Graph method. Also in 1988, Krikelis and Papadakis [10] modeled a simple cycle of the single-shaft gas turbine using the Bond Graph model and then by linearization of the model around an operation point, they designed a PI controller for it. They used the pressure, temperature and torque as the effort variables, and the mass flow and engine speed (rpm) as the flow variables. In 1993, Shoureshi and Brackney [11] in his research, on the use of adaptive active noise control in the engine, modeled a cycle of gas turbine using the Bond Graph method based on the procedure outlined in reference [10]. In 1999, Diston [12] carried out a unified modeling of aerospace systems by the Bond Graph approach. He modeled a virtual aircraft engine by the Bond Graph. In 2001, Pedersen [1] performed the transient performance modeling of the gas turbine system using the Bond Graph method. He developed the energy fields presented by Karnopp and modeled the components of gas turbine system based on them. In his research, the pressure, temperature, torque and fuel factor were considered as the effort variables, and the mass flow, energy flow, engine speed and mass flow of burnt fuel were considered as the flow variables. Thoma and Mocellin [13] in 2006 modeled the components of a gas turbine such as the convergent nozzle, divergent nozzle, stator and rotor using the Bond Graph. In their research, the temperature was considered as the effort variable and the entropy flow as the flow variable. In 2011, Movaghar and Novinzadeh [14] modeled and simulated an ideal turbocharger using the Bond Graph. The purpose of the modeling was to find the system state space equations. In 2014, Sanei et al. [15] considered the effects of kinetic energy and momentum (in the convergent-divergent nozzles with supersonic fluid flows), using the pseudo Bond Graph approach. They also developed the energy field which was able to model the position of vertical shock in the divergent nozzle. Since this field can model the non-isentropic flows, this field can be used to model the thrust of rocket engines and thrusters in the transient states. In 2015, Uddin and Gravdahl [16] developed the Bond Graph model of a radial compressor system to develop the control system. The analysis of Bond Graph model investigates the energy flow of compressor performance in the surge region. Also, they developed some methods to prevent the surge in the compressor. In 2015, Montazeri and Miran Fashandi [17] showed the application of the Bond Graph approach in modeling of cold start phase of the microjet engine. They investigated the possibility of using the combination of compressed air injection with the electric starter by the Bond Graph approach in the cold start phase of the engine. They used a simplified model of microjet engine performance to study the cold start phase.

According to the literature, up to now, no study on modeling and simulating of the dynamic performance of an industrial gas turbine has been done by the Bond Graph. This modeling needs to consider the effects of the inlet guide vanes. Also in earlier studies, the information bonds have not been used to transfer the information to the engine components and to modulate them. But in this paper, the energy fields (as the engine components) were modulated by receiving the information from the information bonds. The objective of this study is to model and simulate the dynamic performance of the industrial gas turbine by the Bond Graph method.

This paper is prepared in seven sections. First, the examined industrial gas turbine engine is described. Next, the thermodynamic $\mathrm{C}$ and $\mathrm{R}$ fields (pseudo Bond Graph 


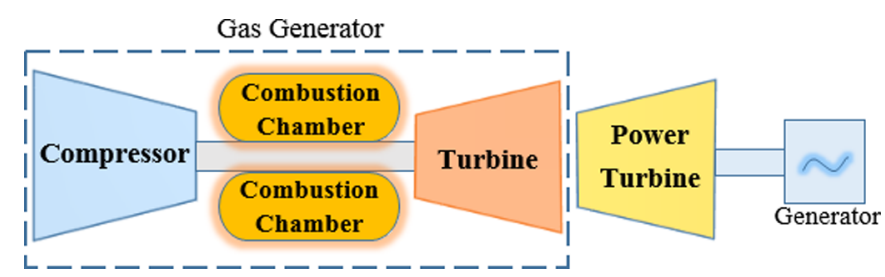

Fig. 1. Schematic of the two-shaft gas turbine.

elements) proposed by Karnopp are developed for the engine components. Subsequently, the complete dynamic model of the gas turbine engine is constructed after coupling the Bond-Graph component models. In the following, the control system is described. Then, the analysis and comparative study of the BG model and GSP simulation results are presented. Finally, the discussions and conclusions are given.

\section{Gas turbine description}

The gas turbine engine studied in this paper is a medium size industrial two-shaft gas turbine, which can be employed in both power generation and mechanical-drive applications [18], and here, the power generation application is considered. This gas turbine engine which known as SGT600, includes an axial compressor with 10 stages that the first two stages have the variable inlet guide vanes. The examined engine also has two bleed valves that open during start and stop to bypass some of the air to avoid surging. The engine specifications in design point condition are listed in Table 1 [18]. The industrial gas turbine under study consists of two distinct parts; the gas generator $(\mathrm{GG})$ and power turbine (PT). The gas generator provides the energy needed to rotate the power turbine and the power turbine uses this power to rotate the generator or compressor depend on the application. As shown in Figure 1, main components of the gas turbine are the compressor, combustion chamber, GG turbine and power turbine. This engine has two separate shafts. The first shaft related to the gas generator is the connector between the compressor and GG turbine and the second shaft connects the power turbine to the compressor or generator (external load).

\section{Bond Graph modelling of gas turbine engine components}

A field is a multiport Bond Graph element. In the following, the engine components have been considered as energy fields. The variables of effort and flow in this section are as the same variables as introduced and selected by Karnopp [19] in the thermo-fluid systems. The selection of these variables causes that the use of the pseudo Bond Graph is more useful than the true Bond Graph. One of the pseudo bonds considers the energy flow as the flow variable and the temperature as the effort variable. The other pseudo bond takes into account the pressure as the effort variable, and the mass flow as the flow variable. Also in the modeling of the compressor and turbine, the torque is selected as the effort variable and the engine speed as the flow variable. Bond Graph modelling of gas turbine systems for dynamic performance has to comply with some very important guidelines to provide useful results: the model must be able to predict steady state performance over a wide area of operating conditions. The model should be as simple as possible, yet able to predict the dynamic operation of interest. The model should include a fairly complete model of the control system, i.e. speed control, temperature limitation, acceleration and deceleration limitation, rate of fuel injection limitation, etc. To develop a workable model for a complete gas turbine system a number of simplifications has to be introduced. First the total system is divided into a number of subsystems such as the compressor, the combustor and turbine. Each of these components having their own model description which are influencing the exchange of mass, energy and work between each of the subsystems. In addition they may introduce changes in the composition of the working medium. Describing the thermodynamic processes which take place in each of the subsystems following the working medium through the complete system is the common denominator of the engine models to be developed.

In developing models for the compressor or turbine basically two different approaches are normally taken. Starting from the fundamental equations for the turbo machine may lead to a correct model, but the number of approximations that must be introduced soon give a model of limited accuracy, at least over a wide operation area. Such an approach also requires a very detailed information of the machine that most manufacturers are extremely reluctant to provide. An approach which is simpler is to start from the steady state performance maps that you may get from the manufacturers. These maps contain the most condensed accurate information of the performance of the machine over a large operational area. The models developed here all use these maps in deriving the model equations (10).

\subsection{Compressor}

For a compressor the mass and energy flow through the machine can be found from compressor performance maps. These maps although they are presented in slightly different versions from different manufacturers, expresses the mass flow and isentropic efficiency as a function of pressure ratio and rotor speed. The assumption that there are no mass or energy accumulation within the compressor and that the time scale for the flow through the compressor is very small compared to the system time scales, allow us to use a quasi-steady approach for the compressor. This means that the steady state performance map for the machine is assumed valid also during transient operation. The performance map of the gas turbine engine under study considers the corrected mass flow rate $\left(\Gamma_{C}\right)$ and isentropic efficiency $\left(\eta_{i s, C}\right)$ of the compressor as a function of the compressor pressure ratio $\left(\pi_{C}\right)$, corrected rotor speed $\left(N_{C, \text { cor }}\right)$ and position of the inlet guide vanes $\left(\theta_{V I G V}\right)$. The compressor characteristic curve of the gas turbine engine under study is shown in Figure 2. With regard to equations (1) and (2), the corrected mass flow rate and isentropic efficiency are achieved from the compressor performance 


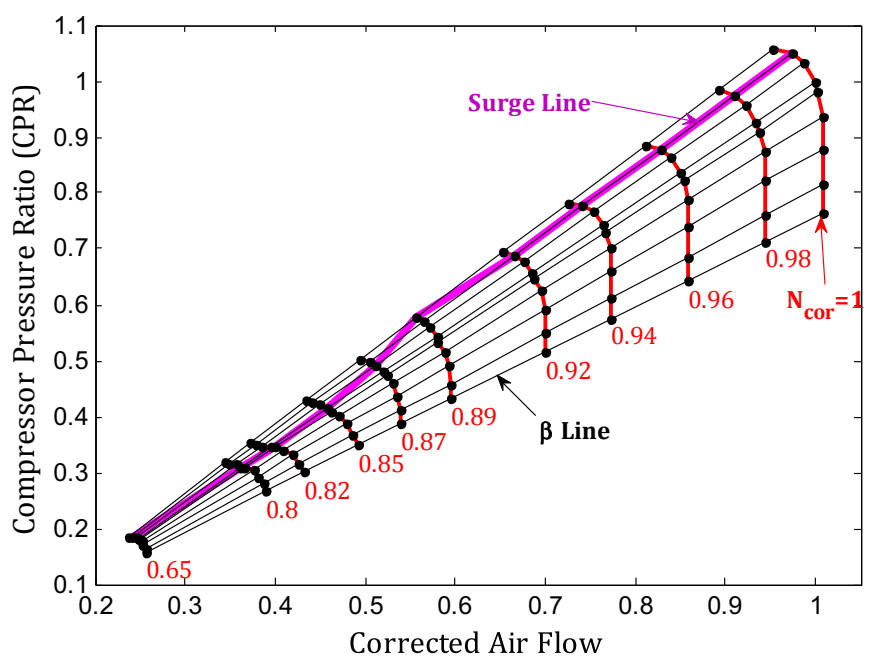

Fig. 2. Compressor performance map.

characteristics curves [20].

$$
\begin{gathered}
\Gamma_{C}=f_{1}\left(\pi_{C}, N_{C, c o r}, \theta_{V I G V}\right), \\
\eta_{i s, C}=f_{2}\left(\pi_{C}, N_{C, c o r}, \theta_{V I G V}\right) \\
\Gamma_{C}=\frac{\dot{m}_{c} \sqrt{\theta}}{\delta}, \quad N_{C, \text { cor }}=\frac{N_{G G}}{\sqrt{\theta}}, \quad \pi_{C}=\frac{P_{\text {out }}}{P_{\text {in }}}
\end{gathered}
$$

where $\delta=P_{i n} / P_{\text {ref }}$ and $\theta=T_{i n} / T_{\text {ref }}$ respectively represent the dimensionless pressure and temperature and $P_{\text {ref }}$ and $T_{\text {ref }}$ represent the standard pressure and temperature (ISA), respectively. $N_{G G}$ and $\dot{m}_{c}$ also introduces the gas generator speed and compressor air mass flow respectively.

In order to consider the effects of the angular position of VIGV on the general performance of the engine, the compressor scale factors should be modified corresponding to $\theta_{V I G V}$ changes. Since the data obtained from the gas turbine test is recorded and displayed by the turbotronic device and this device is merely capable of displaying the percentage of VIGVs openings $(\alpha)$, therefore instead of the angular position of VIGV, the percentage of VIGVs openings should be considered in the calculations. Experimental studies on some axial flow compressors show that the relation between the percentage of VIGVs openings and correction coefficients of the compressor performance map parameters can be expressed through equations (3) and (4) [21].

$$
\begin{gathered}
C P R_{c c o}=\Gamma_{c c o}=2.90667 \times 10^{-3} \alpha+0.819787 \\
\eta_{c c o}=1.66667 \times 10^{-4} \alpha+0.9896667
\end{gathered}
$$

where $C P R_{c c o}, \Gamma_{c c o}$ and $\eta_{c c o}$ represent the correction coefficients of the pressure ratio, corrected mass flow and isentropic efficiency of the compressor, respectively. As can be seen in equations, the amount of correction coefficient to modify the mass flow and pressure ratio is considered the same. By applying the mentioned correction coefficients, the scale factor for parameter $Y\left(S F_{Y}\right)$ can be expressed as

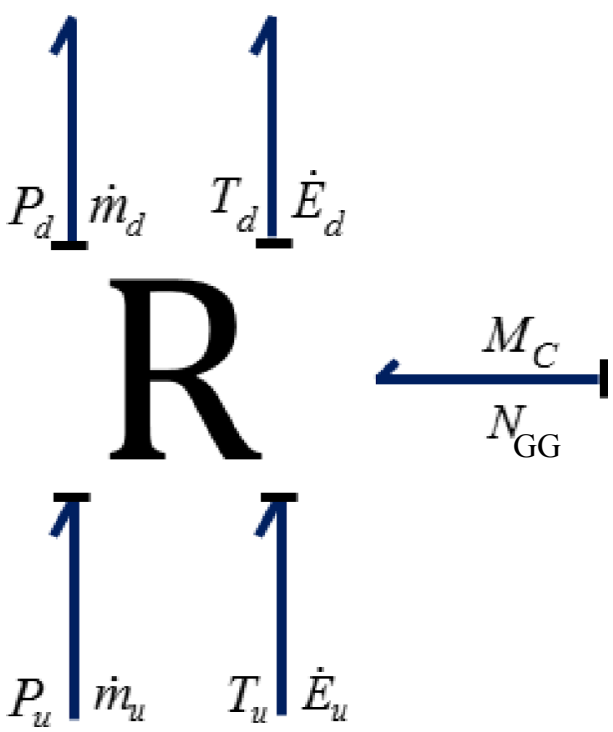

Fig. 3. Compressor pseudo-Bond Graph model.

equation (5).

$$
S F_{Y}=\left(\frac{Y_{d e s}}{Y_{M a p}}\right) Y_{c c o}
$$

where $Y_{\text {des }}$ and $Y_{\text {Map }}$ respectively represent the values of parameter $Y$ (pressure ratio, corrected flow rate or isentropic efficiency) in the design point and reference map, and parameter $Y_{c c o}$ also introduces the relevant correction coefficient.

It should be noted that the purpose of changing the angular position of VIGV is reduction or increase in the flow rate of the compressor inlet air. Usually at low speeds to enlarge the safety performance range of the compressor, by changing the position of VIGV and decreasing the compressor inlet air flow, the possibility of occurring aerodynamic instabilities and surge can be decreased. The compressor shaft torque and exhaust temperature [22] can subsequently be calculated as:

$$
\begin{aligned}
M_{C} & =\frac{30}{\pi}\left[\frac{\eta_{V} \dot{m}_{c}\left(h_{i s, \text { out }}-h_{\text {in }}\right)}{\eta_{\text {is }, c} N}\right], \\
T_{\text {out }}-T_{\text {in }} & =\frac{T_{\text {in }}}{\eta_{C}}\left[\left(\frac{P_{\text {out }}}{P_{\text {in }}}\right)^{\frac{\gamma-1}{\gamma}}-1\right]
\end{aligned}
$$

where $h_{\text {is,out }}$ and $h_{\text {in }}$ is the inflow enthalpy and outflow isentropic enthalpy, $\eta_{V}$ is the volumetric efficiency of the compressor and $\gamma$ is the specific heat ratio. The energy flow in and out of the compressor can subsequently be expressed as:

$$
\begin{aligned}
& \dot{E}_{\text {in }}=\dot{m}_{C} h_{\text {in }, C} \\
& \dot{E}_{\text {out }}=\dot{m}_{C}\left[h_{\text {in }, C}+\frac{\eta_{V}\left(h_{i s, \text { out }, C}-h_{\text {in }, C}\right)}{\eta_{i s, C}}\right]
\end{aligned}
$$

Now, reviewing the model equations derived using a pseudoBond Graph approach, we find that they express a relation between the hydraulic, thermal and mechanical efforts and 
flows on the three ports of the component. The rotational shaft and the fluid inflow and outflow terminals of the compressor, i.e. it is a R-field relation as shown in Figure 3.

The VIGV signal enters to the R-field by an information bond. The information bond is determined in an open loop fashion. This field has the inputs of pressure, temperature and rotational speed, and the outputs of compressor mass flow, energy flow and torque. The preferred causality indicated from the form of the performance maps and the model equations are effort input on all fluid bonds and flow input from the mechanical bond.

The 10-stage compressor is modelled as three compressors in series with two small volume (plenum) in between. From these volumes, two bleed valves are attached for bypassing an amount of air back to the upstream side of the compressor. This does help to avoid surge for low pressures ratios and during acceleration. The plenum is considered to be equivalent to an isentropic passage where both flow speed and energy accumulation are assumed to be negligible[20]. Thus, the following equation is considered across the plenum: T, $P$ (inlet plenum $)=T, P$ (outlet plenum $)$.

Also the pressure and temperature derivative, representing the variation of pressure and temperature due to mass accumulation in the plenum, is calculated using equation (8) that is considered as a C-field in complete Bond Graph model of gas turbine engine in Figure 11.

$$
\begin{aligned}
V_{p} \frac{\mathrm{d} \rho_{\text {out }}}{\mathrm{d} t} & =\frac{V_{P}}{\delta R T_{\text {out }}} \frac{\mathrm{d} p_{\text {out }}}{\mathrm{d} t}=\dot{m}_{\text {in }}-\dot{m}_{\text {out }} \\
\frac{\mathrm{d} T_{\text {out }}}{\mathrm{d} t} & =\frac{\delta}{\rho c_{p} V_{p}}\left(\left(c_{p} T \dot{m}\right)_{\text {in }}-\left(c_{p} T \dot{m}\right)_{\text {out }}\right) \\
& +\frac{T_{\text {out }}}{\rho V_{p}}\left(\dot{m}_{\text {out }}-\dot{m}_{\text {in }}\right)
\end{aligned}
$$

where $V_{P}$ is the volume of the plenum, $c_{p}$ and $\rho$ are heat capacity and density, respectively and $\delta$ can be estimated by the specific heat ratio [20].

\subsection{Combustion chamber}

In the combustion chamber, the combustion process happens by mixing the fuel and compressed air. Combustion gases energy causes to rotate the turbine and generate the work. The input fuel flow rate into the combustion chamber is determined by the control system. The combustion chamber is considered as a constant-volume tank. It is assumed that the process of mixing the fuel and air in the chamber has been completed, and therefore, the physical and chemical properties in the whole of the tank are the same [23].
The non-linear equations of the combustion chamber have been calculated by the conservation laws of mass (Eq. (9)) and energy (Eq. (10)). In this section, the dynamic equations of the model have been extracted by the following steps:

$$
\begin{gathered}
\frac{\mathrm{d} m}{\mathrm{~d} t}=\dot{m}_{\text {in }}-\dot{m}_{\text {out }}+\dot{m}_{f} \\
\frac{\mathrm{d} U}{\mathrm{~d} t}=\dot{m}_{\text {in }} h_{\text {in }}-\dot{m}_{\text {out }} h_{\text {out }}+\dot{m}_{f}\left(h_{f}+L H V \eta_{C \mathrm{C}}\right)
\end{gathered}
$$

where $h_{\text {in }}$ is the input enthalpy, $h_{\text {out }}$ the output enthalpy, $L H V$ the fuel heat value and $\eta_{C C}$ the combustion chamber efficiency. In addition, the internal energy will be as: $U=m C_{V} T$; where $C_{V}$ is the specific heat at constant volume. Derivative of the above equation can lead to obtain equation (11):

$$
\frac{\mathrm{d} U}{\mathrm{~d} t}=C_{V} T \frac{\mathrm{d} m}{\mathrm{~d} t}+C_{V} m \frac{\mathrm{d} T}{\mathrm{~d} t}
$$

By equating equations (10) and (11), the state equation to calculate the chamber exhaust temperature can be written as equation (12):

\section{see equation (12) below}

Using the perfect gas law $(\mathrm{PV}=\mathrm{mRT})$ and equation (12), the following equation to calculate the chamber output pressure will be obtained:

$$
\text { see equation (13) below }
$$

The fuel-air ratio is calculated by the following equation: $f=\frac{m_{f}}{m_{\text {air }}}=\frac{m_{f}}{m-m_{f}}$

According to the above equations, the Bond Graph model of the combustion chamber is shown in Figure 4 as a modulated C-field with the information bonds. This field has two mass flow and energy flow inputs through the energy bonds as well as three pressure, temperature and fuel inputs through the information bonds. Also, the energy field of the combustion chamber has two pressure and temperature outputs through the energy bonds and a fuelair ratio output through the information bond. The preferred causality indicated from the model equations are flow input on all fluid bonds.

\subsection{GG turbine}

Expansion of the hot gases of the combustion and conversion of the gases kinetic energy into the mechanical energy lead to the shaft rotation. To describe the quasistatic behavior of the gas generator and power turbines, a characteristic curve is used. The GG turbine characteristic curve of the gas turbine engine under study is shown in

$$
\begin{gathered}
\frac{\mathrm{d} T}{\mathrm{~d} t}=\frac{\dot{m}_{\text {in }} h_{\text {in }}-\dot{m}_{\text {out }} h_{\text {out }}+\dot{m}_{f}\left(h_{f}+L H V \eta_{C \mathrm{C}}\right)-C_{V} T\left(\dot{m}_{\text {in }}-\dot{m}_{\text {out }}+\dot{m}_{f}\right)}{C_{V} m} \\
\frac{P}{m}\left(\dot{m}_{\text {in }}-\dot{m}_{\text {out }}+\dot{m}_{f}\right) \\
+\frac{P}{T}\left[\frac{\dot{m}_{\text {in }} h_{\text {in }}-\dot{m}_{\text {out }} h_{\text {out }}+\dot{m}_{f}\left(h_{f}+L H V \eta_{C C}\right)-C_{V} T\left(\dot{m}_{\text {in }}-\dot{m}_{\text {out }}+\dot{m}_{f}\right)}{C_{V} m}\right]=\frac{\mathrm{d} P}{\mathrm{~d} t}
\end{gathered}
$$




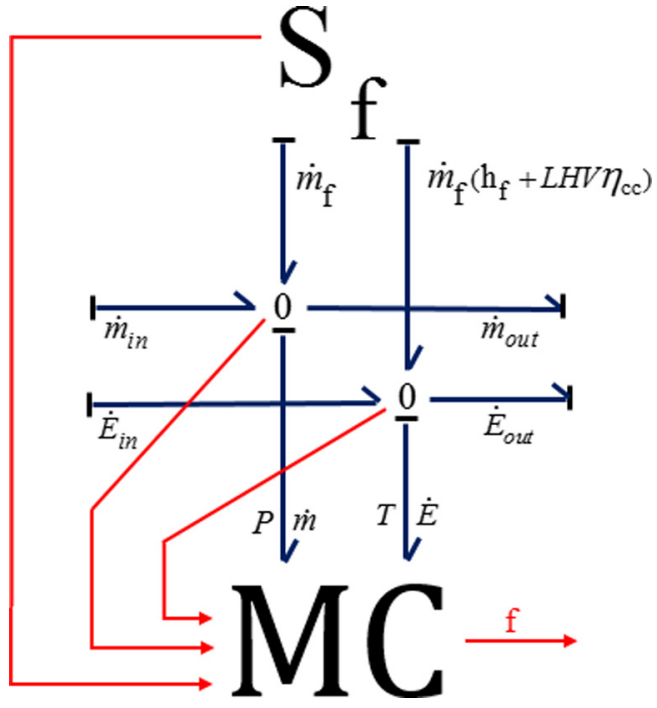

Fig. 4. Combustion pseudo-Bond Graph model.

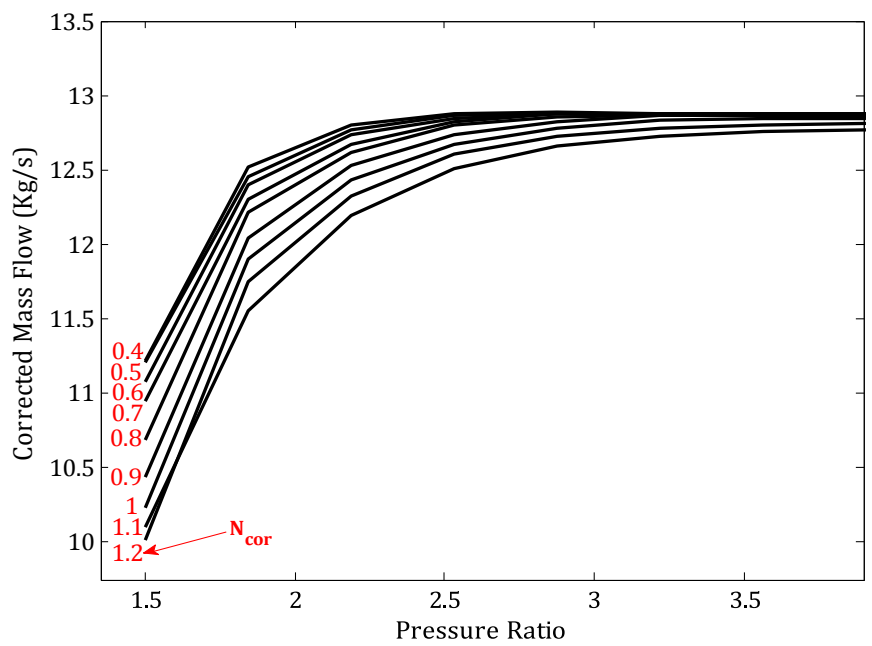

Fig. 5. GG turbine performance map.

Figure 5. The turbine performance map provides the corrected mass flow rate $\left(\Gamma_{T}\right)$ and isentropic efficiency $\left(\eta_{i s, T}\right)$ as a function of the expansion ratio $\left(\pi_{T}\right)$ and corrected rotor speed $\left(N_{T, c o r}\right)$. According to equations (14) and (15), the mass flow rate and isentropic efficiency are obtained using the turbine characteristic curves [22].

$$
\begin{aligned}
& \Gamma_{T}=g_{1}\left(\pi_{T}, N_{T, c o r}\right), \quad \eta_{i s, T}=g_{2}\left(\pi_{T}, N_{T, \text { cor }}\right) \\
& \Gamma_{T}=\frac{\dot{m}_{T} \sqrt{\theta}}{\delta}, \quad N_{T, \text { cor }}=\frac{N_{G G}}{\sqrt{\theta}}, \quad \pi_{T}=\frac{P_{\text {in }}}{P_{\text {out }}}
\end{aligned}
$$

Similar to the compression process in the compressor, the expansion process in the turbine is also considered as an isentropic process. The turbine output torque in an isentropic process can be calculated by equation (16).

$$
M_{T}=\frac{30}{\pi}\left[\frac{\eta_{T} \dot{m}_{T}\left(h_{u}-h_{d, i s}\right)}{N}\right]
$$

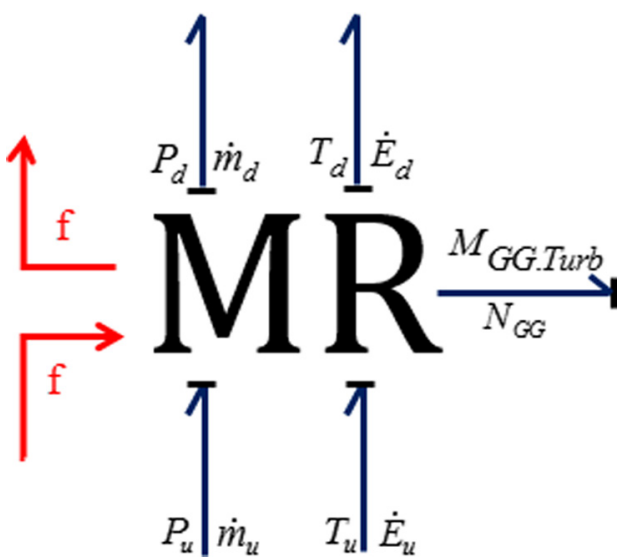

Fig. 6. GG turbine pseudo-Bond Graph model.

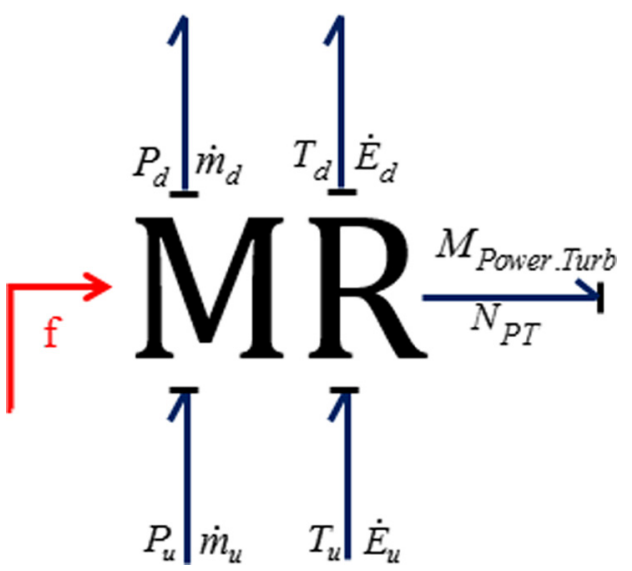

Fig. 7. Power turbine pseudo-Bond Graph model.

The energy flow in and out of the turbine can subsequently be expressed as:

$$
\begin{aligned}
& \dot{E}_{\text {in }}=\dot{m}_{T} h_{u, T} \\
& \dot{E}_{\text {out }}=\dot{m}_{T}\left[h_{u, T}+\frac{\left(h_{u}-h_{d, i s}\right)}{\eta_{T}}\right]
\end{aligned}
$$

Now, by reviewing the model equations, the modulated R-field can be defined as shown in Figure 6. The chamber output pressure and temperature, rotational speed, GG turbine pressure and temperature are considered as the field inputs, and the GG turbine mass flow and energy flow and torque as the field outputs. Using an information bond, the fuel-air ratio of the combustion chamber enters into the GG turbine and then it is sent to the power turbine and plenum by the other information bond. The plenum is put between the GG turbine and the power turbine. The preferred causality indicated from the model equations are effort input on all fluid bonds and flow input from the mechanical bond.

\subsection{Power turbine}

The turbine performance map provides the corrected mass flow rate and isentropic efficiency as a function of the expansion ratio and corrected rotor speed. According to 


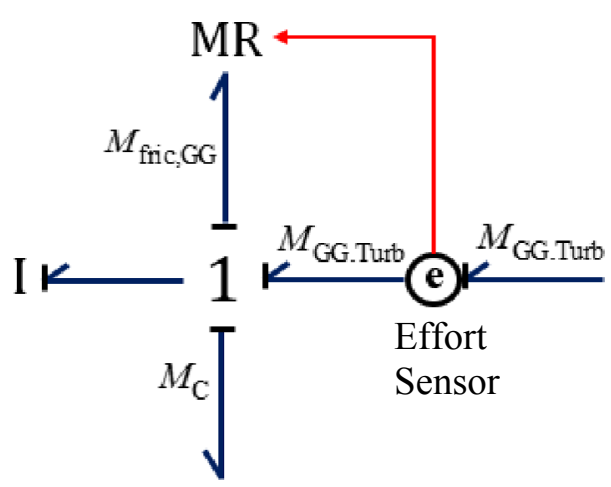

(a)

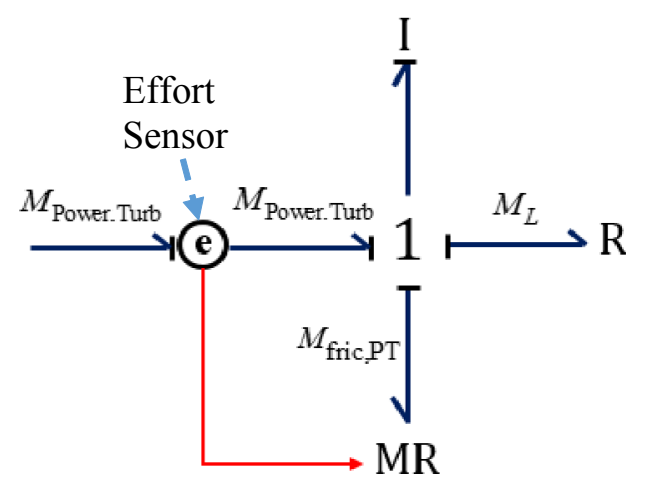

(b)

Fig. 8. Bond graph representation of the engine shafts models: (a) GG shaft model and (b) PT shaft model.

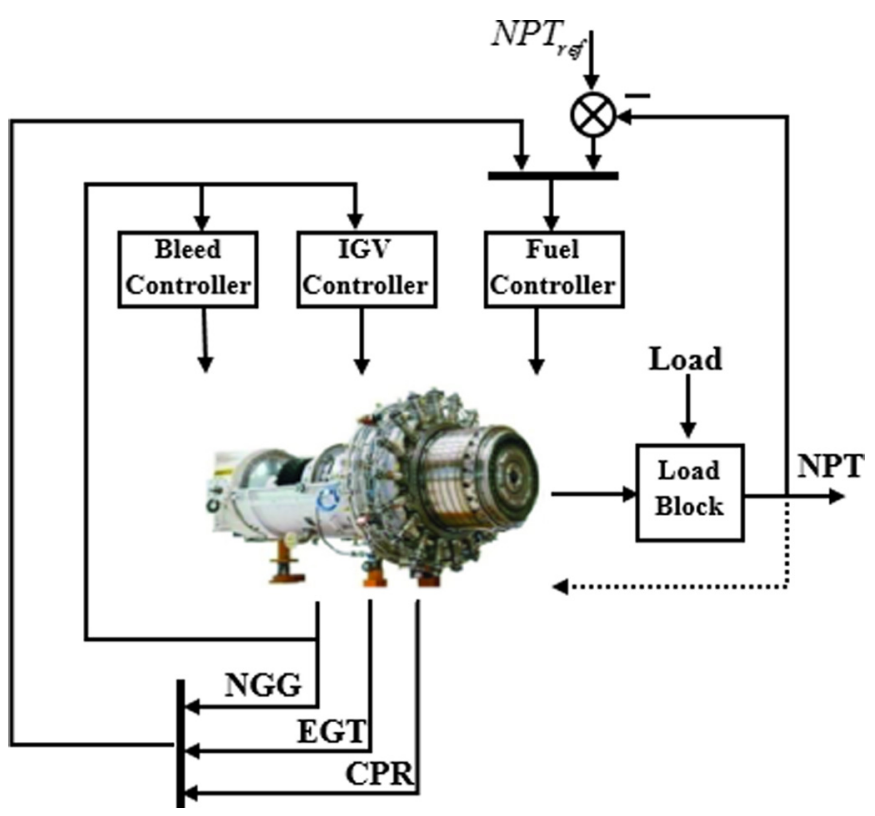

Fig. 9. Schematic representation of the gas turbine engine control circuit.

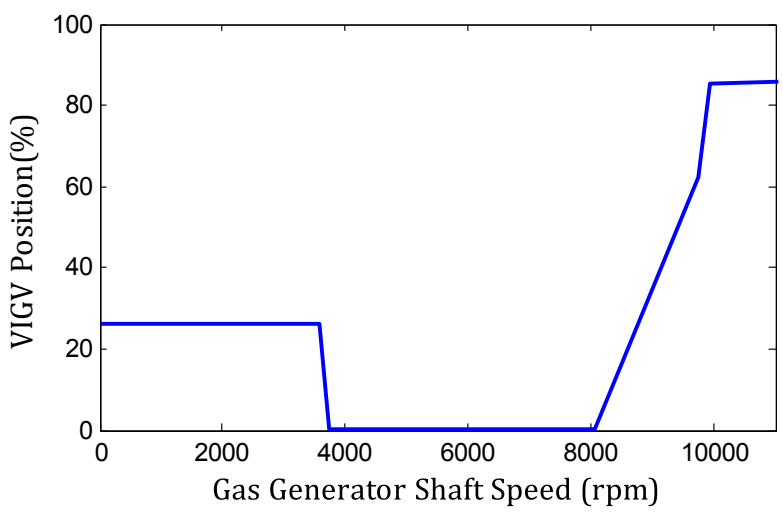

Fig. 10. VIGV position against GG shaft speeds.

equations (14) and (15), the mass flow rate and isentropic efficiency are obtained using the turbine characteristic curves. The modulated R-field for the power turbine can be defined as presented in Figure 7. The GG turbine output pressure and temperature, rotational speed, ambient pressure and temperature are considered as the field inputs, and the power turbine mass flow and energy flow and torque as the field outputs. The fuel-air ratio of the GG turbine enters to the power turbine by an information bond. The preferred causality indicated from the model equations are effort input on all fluid bonds and flow input from the mechanical bond.

\subsection{Engine shaft model}

The imbalance between the generated power by the turbine (output shaft) and the consumed power in the compressor can cause the acceleration of the gas generator shaft. As the same way, changes in the load applied to the power turbine shaft can also be a factor for changing the power turbine speed and accelerating the connector shaft between the generator and power turbine. In a two-shaft gas turbine, the dynamic behavior of the gas generator shaft and power turbine shaft can be described by equations (20) and (21), where in these equations, $I$ and $N$ respectively represent the moment of inertia and rotational speed of the gas generator and power turbine shafts. $M_{L}$ in equation (21) represents the consumed torque due to the imposed load on the power turbine shaft (consumed generator torque). $M_{\text {fric }}$ in equation (19) represents the friction torque that is proportional to the shaft torque from the turbine with coefficient of the mechanical efficiency [22].

$$
\begin{gathered}
M_{\text {fric }, G G}=\eta_{\text {mech }, G G} M_{G G . T u r b} \\
M_{\text {fric }, P T}=\eta_{\text {mech }, P T} M_{\text {Power.Turb }} \\
\frac{\mathrm{d} N_{G G}}{\mathrm{~d} t}=\frac{30}{\pi I_{G G}}\left(M_{G G . T u r b}-M_{C}-M_{\text {fric }, G G}\right) \\
\frac{\mathrm{d} N_{P T}}{\mathrm{~d} t}=\frac{30}{\pi I_{P T}}\left(M_{\text {Power.Turb }}-M_{L}-M_{\text {fric }, P T}\right)
\end{gathered}
$$

The related Bond Graph models are shown in Figure 8. 


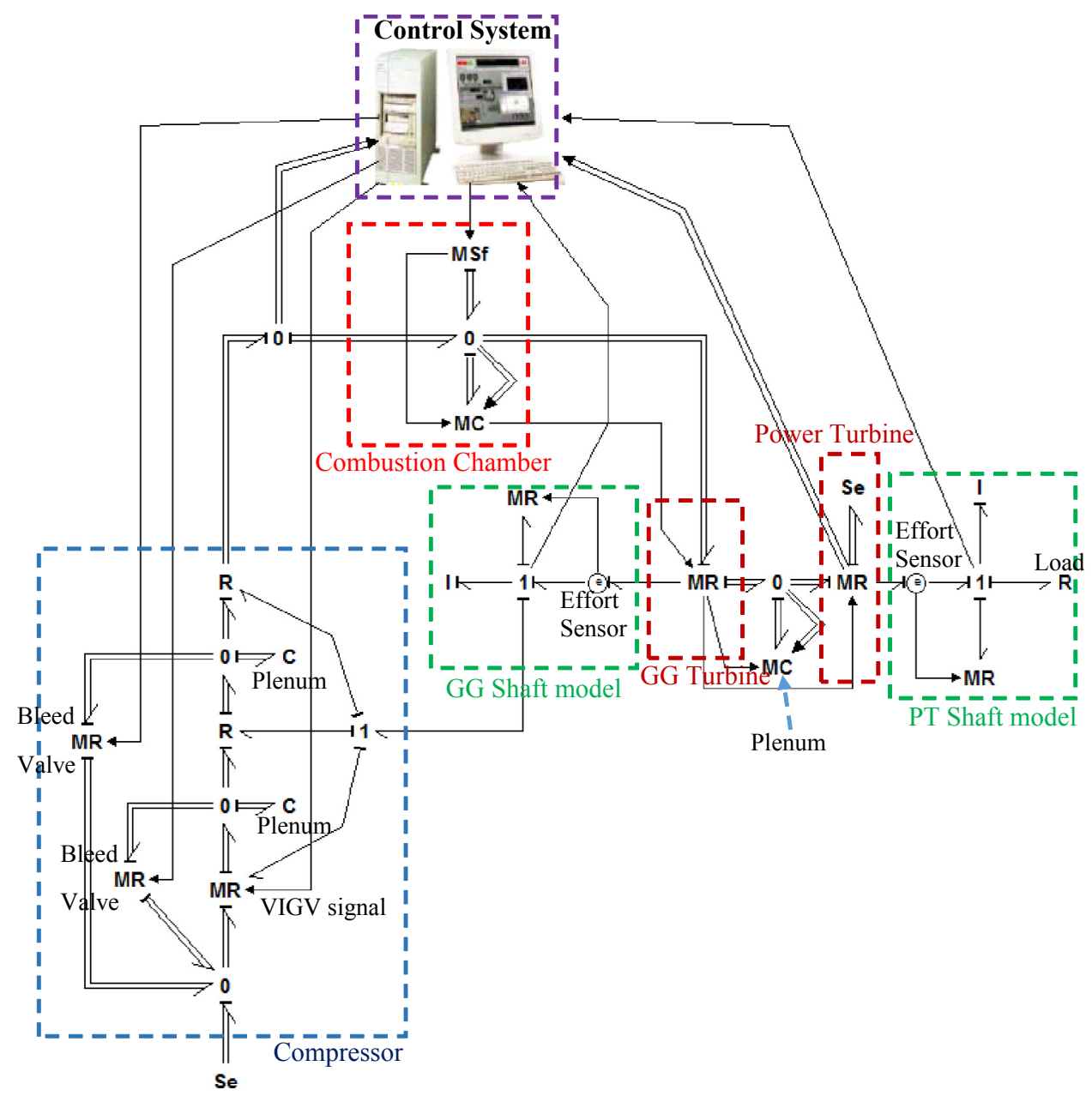

Fig. 11. Complete bond graph model of the gas turbine engine.

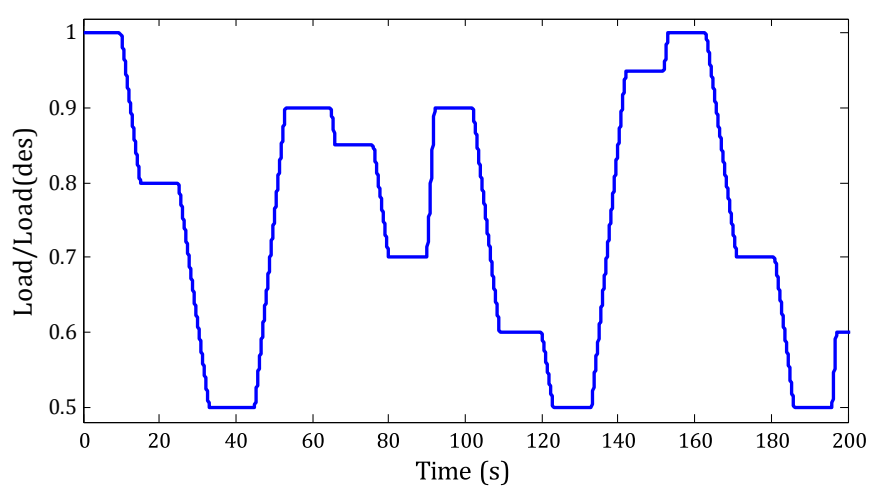

Fig. 12. Normalized input load.

\section{Description of control system}

Figure 9 shows the schematic of the gas turbine engine control circuit. Under the standard conditions, the turbogenerators control system has two forms; the droop control and isochronous control [24]. In this study, the isochronous control strategy was used to control the turbo-generator load/speed. When a turbo-generator unit is in the isochronous control mode, the control system must change the control parameters in a way that the power turbine speed (output frequency) remains constant. In fact, the change of loading causes the power turbine speed deviation from the desired value and the controller is responsible for the appropriate change in the fuel flow rate during the shortest possible time to restore the power turbine speed to the initial value. The fuel controller block is depicted in Figure 9 includes an isochronous controller and a set of limiters that in addition to stabilizing the power turbine speed, is also responsible for satisfying the engine's physical and aerodynamic constraints.

As previously described, the examined gas turbine compressor have variable inlet guide vanes and hence, in addition to the fuel flow rate, the angular position of the variable inlet guide vanes (i.e. $\theta_{V I G V}$ ) can also be considered as the second control parameter. For the examined gas turbine, the control of $\theta_{V I G V}$ is as open loop control based on the data presented in Figure 10, which means that the desired position of the variable inlet guide vanes is merely a function of the gas generator speed. Also, the valve positions of bleed valves are functions of the gas generator speed [25]. Loading block (in Fig. 9) receives the external load and output power of the power turbine as inputs and by balancing the power for the power turbine rotor, the instantaneous value of NPT can be determined. The controller can also be extended to control a by-pass valve between different stages of the compressor. 


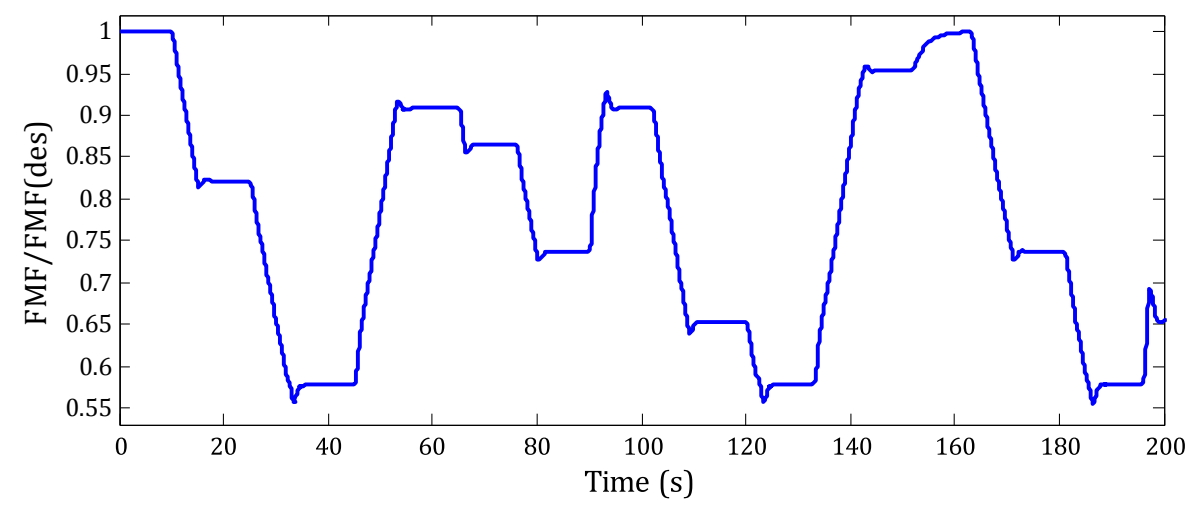

Fig. 13. Normalized fuel mass flow.

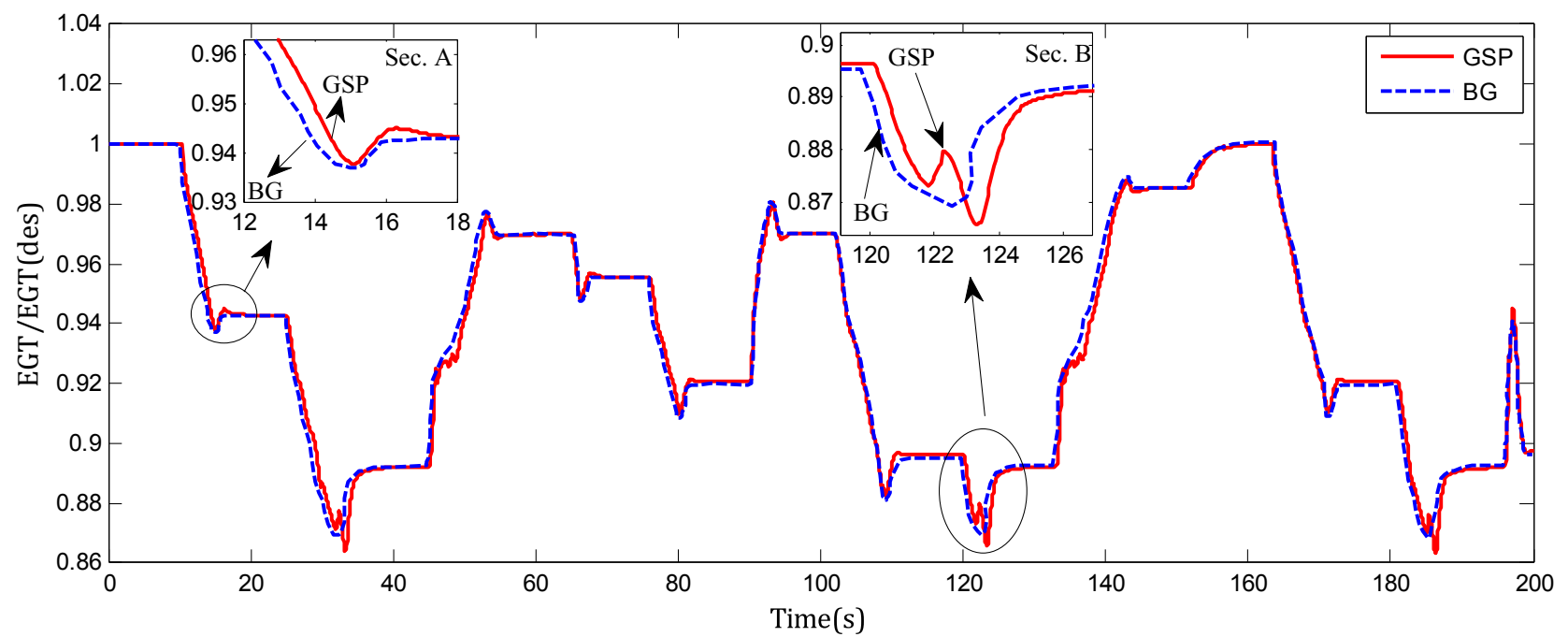

Fig. 14. Comparison of BG model and GSP for EGT.

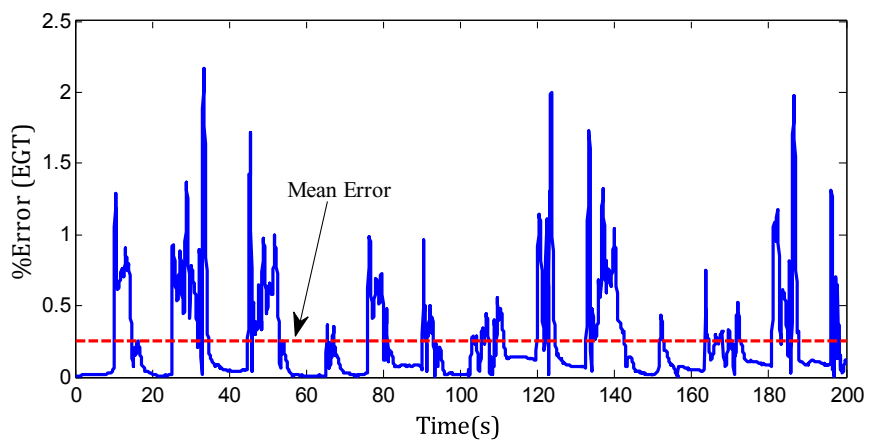

Fig. 15. The percentage of error between BG model and GSP for EGT.

\section{Complete Bond Graph model of gas turbine engine}

The complete dynamic model of the gas turbine engine is constructed after coupling the Bond-Graph sub-models. As shown in Figure 11, there is a one-to-one map between the components modeled by the Bond Graph and the gas turbine engine components shown in Figure 1. It shows the ability of the Bond Graph approach in the modular modeling of the system components. Using this feature a model libraries which consists of the systems made from the gas turbine engine components can be developed.

In Figure 11, after determining the effort and flow in the gas turbine system, the type of engine component elements must be specified. In this study, the environment was considered as a source of effort and the fuel mass flow as a source of flow. Due to the assumption that no energy is stored in the compressor and turbine, these were considered as the energy dissipater elements (resistance). The combustion chamber and shaft dynamics were modeled as the energy capacitor elements (i.e. capacitor and inertia). In the next step, after the Bond Graph modeling of the engine components, these elements were connected together by the energy and information bonds, and zero and one junctions. In the engine model, the energy enters into the system via the source of effort (environment) and the source of flow (fuel flow rate). The Bond Graph model, developed in this study, is based on the exchange of energy and power between the engine components. It means that the effort and flow are exchanged between the components. The product of these two parameters is representative of the power, and the integral of power represents the energy. 


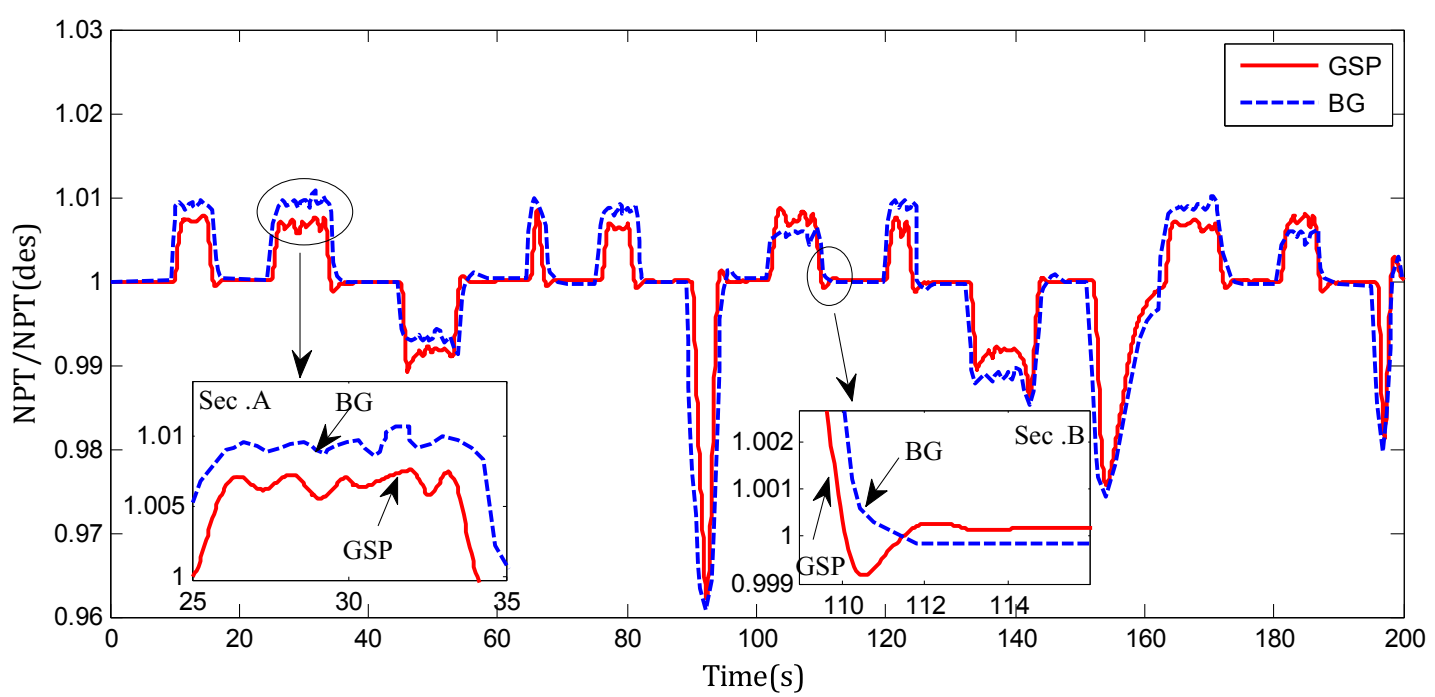

Fig. 16. Comparison of BG model and GSP for NPT.

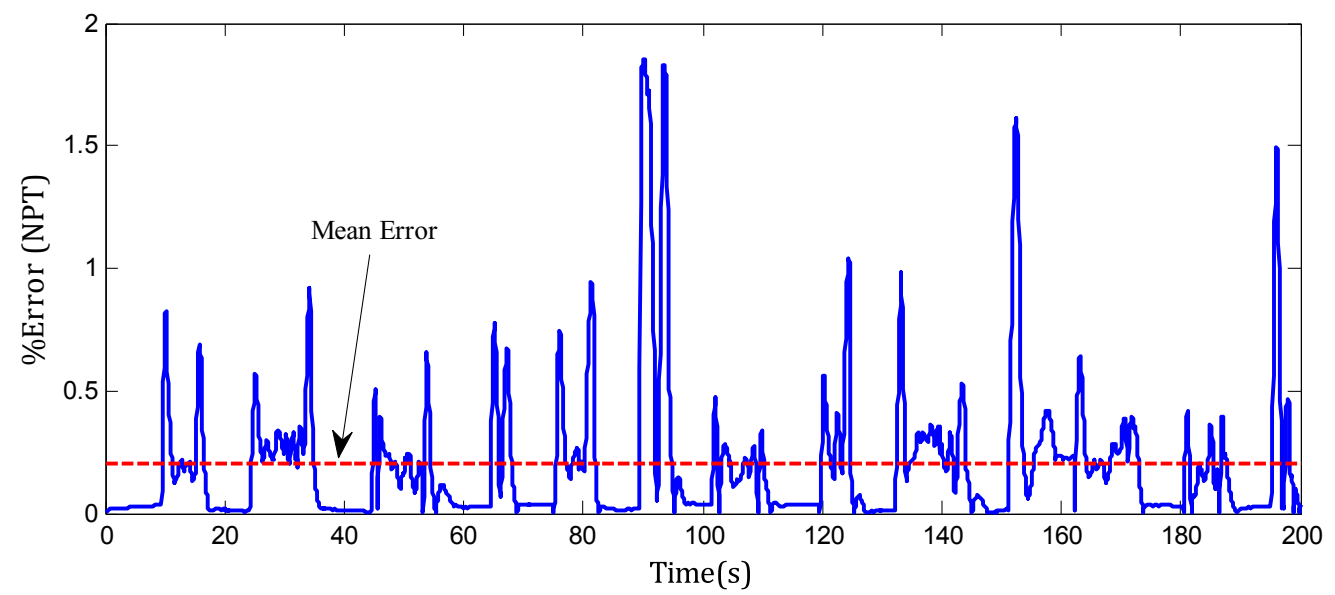

Fig. 17. The percentage of error between BG model and GSP for NPT.

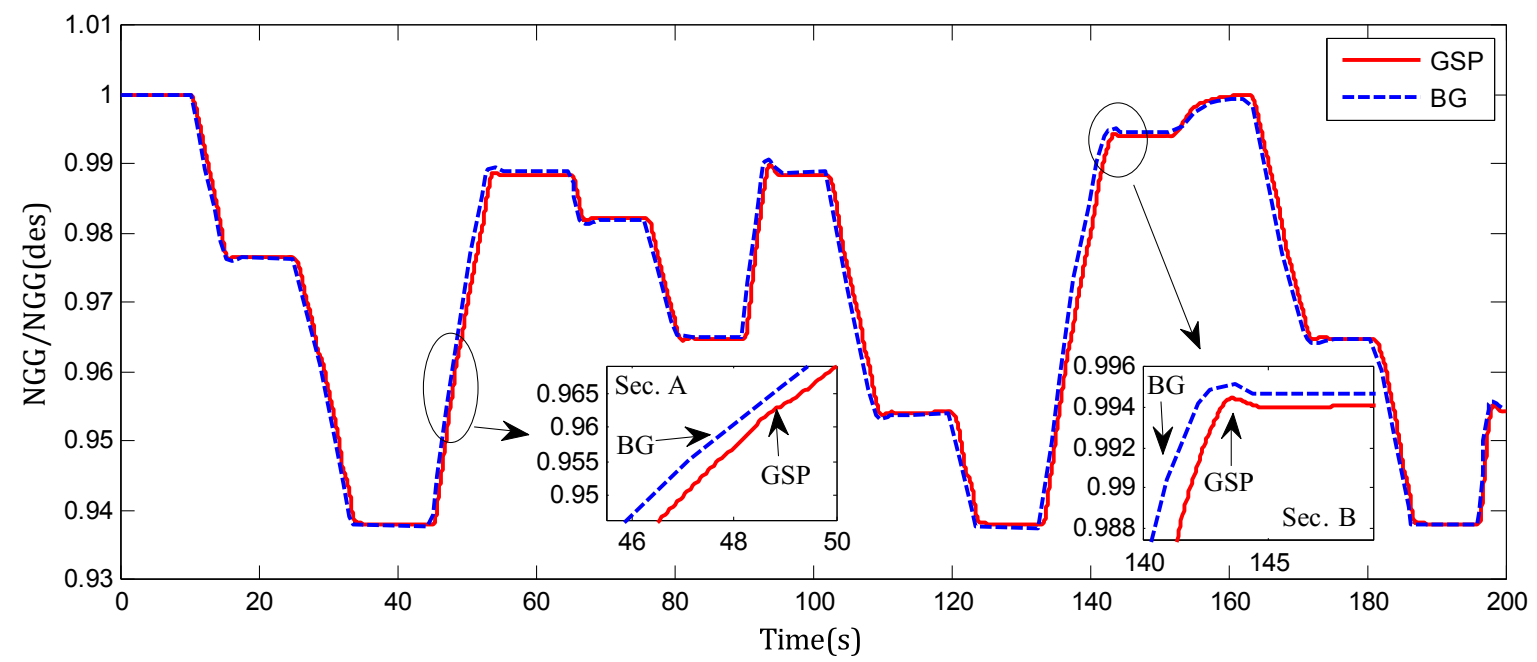

Fig. 18. Comparison of BG model and GSP for NGG. 


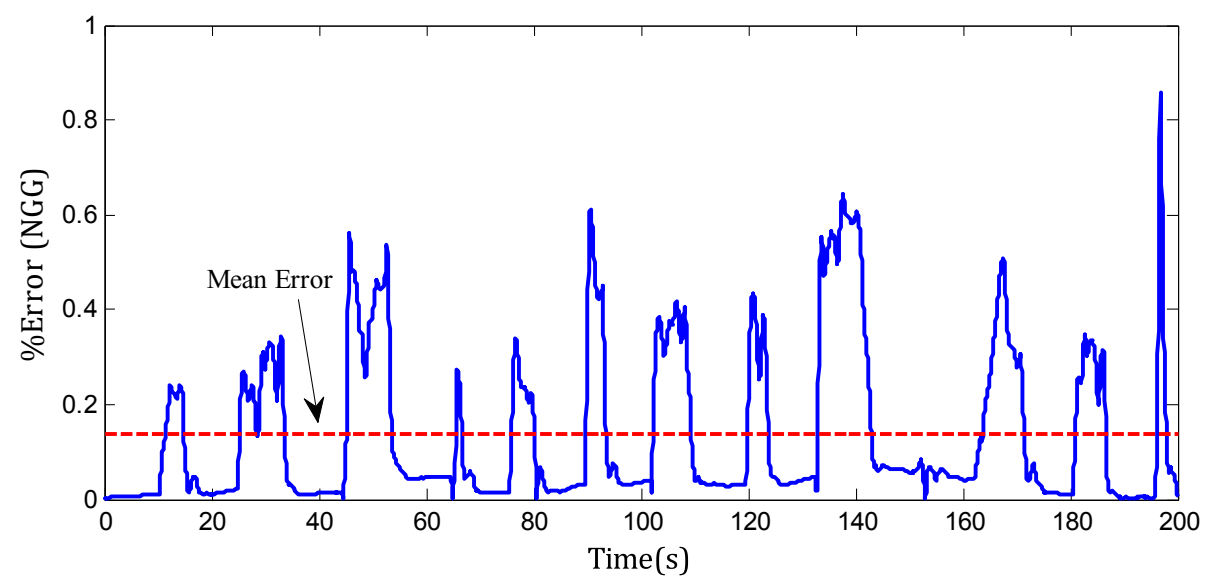

Fig. 19. The percentage of error between BG model and GSP for NGG.

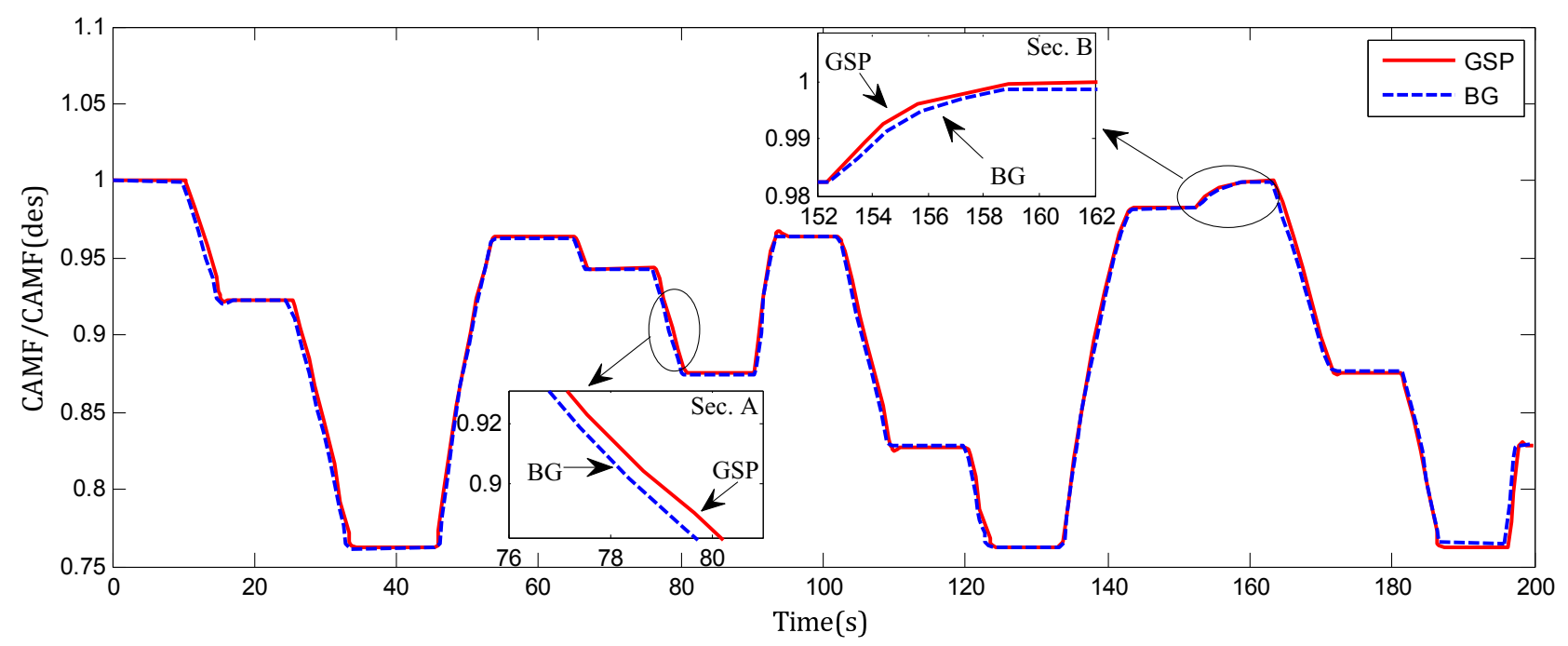

Fig. 20. Comparison of BG model and GSP for CAMF.

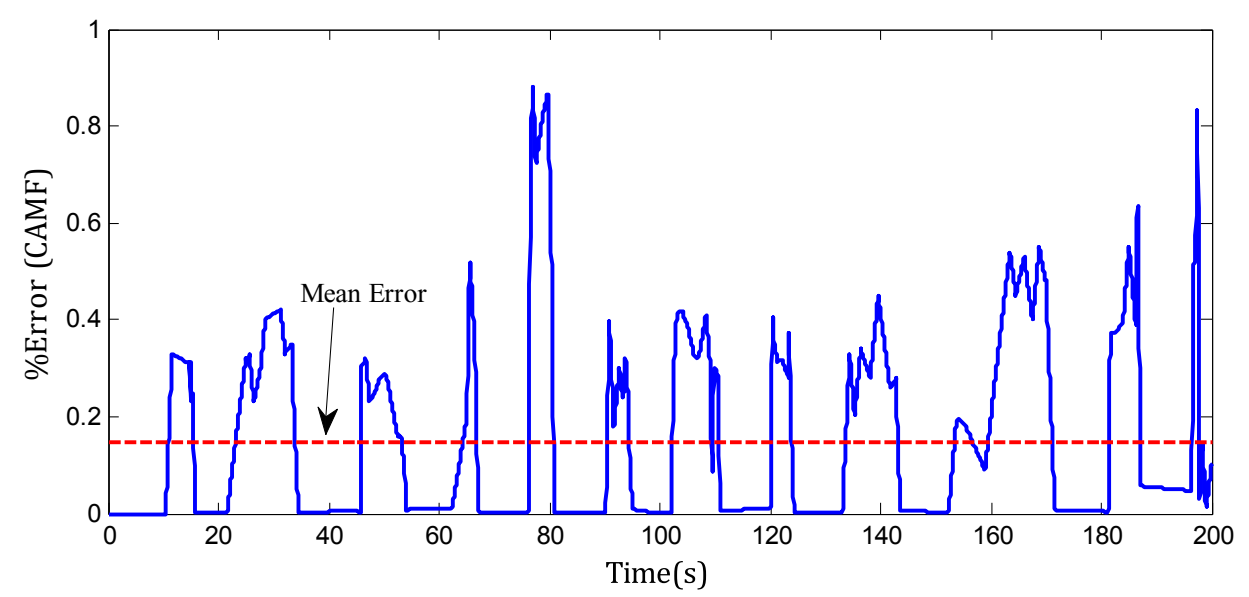

Fig. 21. The percentage of error between BG model and GSP for CAMF. 
Table 2. BG model and GSP simulation results maximum and mean percent error.

\begin{tabular}{lll}
\hline & Maximum error $(\%)$ & Mean error $(\%)$ \\
\hline EGT & 2.17 & 0.2526 \\
NPT & 1.85 & 0.2022 \\
NGG & 0.86 & 0.1379 \\
CAMF & 0.88 & 0.1472 \\
\hline
\end{tabular}

In other words, the output effort or flow of each engine component is algebraically or differentially related to the effort or input flow to that element.

\section{Analysis of the simulation and results}

In this study, external loading has been changed based on a given profile. The control system determines the instantaneous value of the fuel flow proportional to the applied load, to stabilize NPT and satisfy the system physical constraints. Figure 12 shows the procedure of loading on the power turbine. On the other hand, in order to compare the results of the Bond Graph model with the GSP [26] (software), the external load profile was applied in GSP software. Figure 13 shows the fuel flow variations in terms of the applied load. Using Figures 14, 16, 18 and 20 the performance of the Bond Graph and GSP models in estimating the parameters EGT, NPT, NGG and CAMF can be compared with each other. Figures 15, 17, 19 and 21 show the error percentage of above parameters. Table 2 shows the maximum and mean percent error of the Bond Graph model EGT, NPT, NGG, and CAMF values from the GSP values over the simulations. As can be seen in Table 2, the maximum percent errors of performance parameters are found to be below $2.2 \%$ over a wide load ranges, with the mean percent errors below $0.26 \%$. These results show that the Bond Graph model is acceptable for approximating the GSP model output. As can be seen in Figure 16, by changing in the applied load, the power turbine speed deviates from its nominal value but the isochronous mode controller, returns NPT to its nominal value during a short time by simultaneously managing the fuel flow and subsequently changing the turbine's output power. Since the control system must keep the power turbine speed constant, when the load applied on the system is reduced, the fuel injected into the combustion chamber is decreased. This causes to increase in the amount of air to fuel ratio, and rises the risk of flame-out. So, the control system regulates the angular position of the variable inlet guide vanes and thus reduces CAMF (Fig. 20) to prevent the flame-out. As the load rises, both FMF and $\theta_{I G V}$ are used to regulate NPT. In this way, the amount of FMF is increased to prevent NPT reduction. A rapid increase in the input fuel entering the combustion chamber, to achieve NPT around the full speed (100\%) and to increase the system response speed, causes an inevitable increase in EGT (Fig. 14). High values of EGT indicate high internal temperature which result in turbine blade damage. In fact, because of increase in the input fuel in a short moment, a greater power than the generator turbine output power in the design point enters to the power turbine and, therefore, the power turbine response speed increases. In the first moments of accelerating, a sudden fuel injection into the combustion chamber and consequently the sudden increase in CPR and NGG (Fig. 18) are the main causes of occurring the aerodynamic instabilities such as surge and stall. The limiting loops such as rotational speed and acceleration loops preserve the gas turbine from exceeding the operational limitations. In acceleration mode, since air and FMF are varying at the same rate, sudden raise in EGT occurs but the EGT limiting loop keeps it at safe region.

\section{Conclusions}

In this paper, modeling and simulation of the industrial gas turbine dynamic performance is achieved based on the pseudo Bond Graph approach. To do this, we first obtained the physical relationships governing each engine component in conjunction with the performance characteristic curves of the compressor and turbine. Next, the modulated energy fields (pseudo Bond Graph elements) were developed for the gas turbine components. The complete dynamic model of the gas turbine is constructed after coupling the Bond Graph sub-models. Also, the gas turbine simulation program (GSP) is used to validate the simulation results. The maximum percent errors of performance parameters are found to be below $2.2 \%$ over a wide load ranges, with the mean percent errors below $0.26 \%$. The presented comparisons show the good accuracy of the results. The proposed model can readily be used as a subsystem for the larger systems like power plants. It can also be applied as the basis for innovative design of control and diagnosis systems associated with industrial gas turbines.

\section{Nomenclature}

BG Bond Graph

GSP gas turbine simulation program

EGT exhaust gas temperature

FMF fuel mass flow

NGG gas generator speed

NPT power turbine speed

CAMF compressor air mass flow

CPR compressor pressure ratio

VIGV variable inlet guide vane

GG gas generator

PT power turbine

$N \quad$ rotational speed

e effort sensor 


\section{References}

[1] E. Pedersen, Modelling gas turbine systems for transient performance using Bond Graphs, in: 13th European Simulation Symposium and Exhibition, Bond Graphs Workshop, Marseilles, France, October 18-20, 2001

[2] W.I. Rowen, Simplified mathematical representations of heavy-duty gas turbines, ASME J. Eng. Gas Turbines Power 105 (1983) 865-869

[3] C. Evans, D. Rees, Frequency-domain identification of gas turbine dynamics, IEEE Trans. Control Syst. Technol. 6 (1998) 651-662

[4] H. Saravanamuttoo, A.J. Fawke, Simulation of gas turbine dynamic performance, in: ASME Gas Turbine Conference, Paper 70-GT-23, 1970, pp. 1-8

[5] Q.Z. Al-Hamdan, M.S. Ebaid, Modeling and simulation of a gas turbine engine for power generation, ASME J. Eng. Gas Turbines Power 128 (2005) 302-311

[6] S. Lu et al., Bond-graph model of a piezo stack driven jetting dispenser, Simul. Model. Pract. Theory 49 (2014) 193-202

[7] J.U. Thoma, Entropy and mass flow for energy conversion, J. Frankl. Inst. 299 (1977) 319-328

[8] D.C. Karnopp, State variables and pseudo Bond Graphs for compressible thermo-fluid systems, Trans. ASME J. Dyn. Syst. Meas. Control 101(3) (1979) 201-204

[9] L. Markunasa, Modeling, simulation and control of gas turbines, M.S. thesis, Department of Mechanical Engineering, M.I.T., Massachusetts, 1972

[10] N.J. Krikelis, F. Papadakis, Gas turbine modelling using pseudo-Bond Graphs, Int. J. Syst. Sci. 19 (1988) 537-550

[11] R. Shoureshi, L. Brackney, Applications of active adaptive noise control to jet engines, 1993

[12] D.J. Diston, Unified modelling of aerospace systems: a Bond Graph approach, Diss. University of Glasgow, 1999

[13] J.U. Thoma, G. Mocellin, Simulation with entropy in engineering thermodynamics, Springer, Berlin, 2006

[14] A.R.S. Movaghar, A. Novinzadeh, Ideal turbo charger modeling and simulation using Bond Graph approach, in: ASME 2011 Turbo Expo: Turbine Technical Conference and Exposition, American Society of Mechanical Engineers, 2011, pp. 871-879
[15] A. Sanei, A.B. Novinzadeh, M. Habibi, Addition of momentum and kinetic energy effects in supersonic compressible flow using pseudo Bond Graph approach, Math. Comput. Model. Dyn. Syst. 20(5) (2014) 491-503

[16] N. Uddin, J.T. Gravdahl, Bond graph modeling of centrifugal compression systems, Simulation 99(11) (2015) 998-1013

[17] M.-G. Montazeri, S.A. Miran Fashandi, Application of bondgraph method in microjet engine cold start modeling to investigate the idea of injecting compressed air, in: Applied Mechanics and Materials, vol. 799, Trans Tech Publications, Zorikh, Switzerland, 2015

[18] SGT-600 Industrial Gas Turbine, Siemens Industrial Turbomachinery, Duisburg, Germany, 2005, Available from: http://www.energy.siemens.com/ru/pool/hq/power-genera tion/gas-turbines/SGT-600/downloads/SGT-600_GT_Po werGen_EN.pdf

[19] D.C. Karnopp, D.L. Margolis, R.C. Rosenberg, System dynamics: modeling, simulation, and control of mechatronic systems, John Wiley \& Sons, Hoboken, NJ, 2012

[20] S. Camporeale, B. Fortunato, M. Mastrovito, A modular code for real time dynamic simulation of gas turbines in Simulink, ASME J. Eng. Gas Turbines Power, 128 (2006) 506-517

[21] B.T. Aklilu, S.I. Gilani, Mathematical modeling and simulation of a cogeneration plant, Appl. Therm. Eng. 30 (2010) 2545-2554

[22] R. Chacartegui, D. Sanchez, A. Muonoz, T. Sanchez, Real time simulation of medium size gas turbines, Energy Convers. Manag. 52 (2011) 713-724

[23] J.H. Kim, T.W. Song, T.S. Kim, S.T. Ro, Model development and simulation of transient behavior of heavy duty gas turbines, ASME J. Eng. Gas Turbines Power, 123 (2000) 589-594

[24] S. Massucco, S. Pitto, F. Silvestro, A gas turbine model for studies on distributed generation penetration into distribution networks, IEEE Trans. Power Syst. 26 (2011) 992-999

[25] T. Strand, Industrial gas turbine control, in: Siemens Power Generation, Siemens AG, Erlangen, Germany, 2006. Available at: www.energy.kth.se/courses/4a1626/ahpt2006/gtcontrol.pdf

[26] W.P.J. Visser, M.J. Broomhead, GSP, a generic objectoriented gas turbine simulation environment, in: ASME turbo expo 2000: power for land, sea, and air, American Society of Mechanical Engineers, Munich, Germany, 2000

Cite this article as: M. Montazeri-Gh, S.A.M. Fashandi, Application of Bond Graph approach in dynamic modelling of industrial gas turbine, Mechanics \& Industry 18, 410 (2017) 